\title{
Simvastatin in the treatment of asthma: lack of steroid-sparing effect
}

\author{
Douglas C Cowan, Jan 0 Cowan, Rochelle Palmay, Avis Williamson, D Robin Taylor
}

- Additional methods, figures and tables are published online only. To view these files please visit the journal online (http:// thorax.bmj.com).

Dunedin School of Medicine, University of Otago, Dunedin, New Zealand

\section{Correspondence to} Professor D Robin Taylor, Dunedin School of Medicine, University of Otago, PO Box 913, Dunedin, New Zealand; robin.taylor@stonebow.otago. ac.nz

Received 16 March 2010 Accepted 10 June 2010

\section{ABSTRACT}

Background Statins have anti-inflammatory actions which in theory are potentially beneficial in asthma. Small trials have failed to show a significant benefit, but a systematic study to evaluate the steroid-sparing effect of statin treatment has not been carried out.

Methods A randomised, placebo-controlled, crossover trial was conducted of simvastatin $40 \mathrm{mg}$ at night with simultaneous stepwise reduction of fluticasone propionate dose until loss of control occurred, followed by an increase until regain of control ('minimum' dose required) in 51 patients with asthma and sputum eosinophils (steroid-free) $\geq 2 \%$.

Results 43 patients completed the study. There was no significant difference in 'minimum' inhaled corticosteroid (ICS) dose requirement between simvastatin and placebo: (median (IQR) $50 \mu \mathrm{g}$ daily (0-250) vs $100 \mu \mathrm{g}$ daily (0-250), $p=0.931)$. 'Minimum' dose distribution was similar $(p=0.269)$. The fluticasone dose at which loss of control occurred did not differ significantly between simvastatin and placebo $(p=0.404)$. In patients with loss of control in both treatment arms, fluticasone dose at loss of control was similar with simvastatin and placebo (median (IOR) $50 \mu$ g daily (0-100) for both, $\mathrm{p}=0.620$ ). In those patients who reached $0 \mu \mathrm{g} / \mathrm{day}$ $(n=18)$, Astma Control Questionnaire (ACQ) was lower $(p=0.037)$, forced expiratory volume in $1 \mathrm{~s}\left(\mathrm{FEV}_{1}\right)$ higher $(p<0.01)$ and sputum eosinophils lower with simvastatin compared with placebo $(9.5 \%$ compared with $25.4 \%, p=0.033$ ).

Conclusions Simvastatin does not have clinically important steroid-sparing effects in patients with eosinophilic asthma. In the absence of steroid, simvastatin is associated with minor improvements in symptoms and lung function, and a reduction in sputum eosinophils.

Clinical trial number ACTRN12606000531516.

\section{INTRODUCTION}

Statins have anti-inflammatory as well as cholesterol-lowering effects. ${ }^{1}$ They may be beneficial in cardiovascular disease, ${ }^{2}$ multiple sclerosis ${ }^{3}$ and rheumatoid arthritis. ${ }^{4}$ In chronic obstructive pulmonary disease (COPD), ${ }^{5}$ their use is associated with reduced decline in lung function, ${ }^{6}$ improved survival following exacerbations ${ }^{7}$ and increased exercise capacity. ${ }^{8}$

In asthma, there are theoretical reasons why statins might exert therapeutic effects. Their actions include reducing both $\mathrm{T}$ cell proliferation and activation, and leucocyte migration. ${ }^{9}$ In animal models, statins inhibit eosinophilic infiltration into the lung, ${ }^{10} 11$ reduce airway hyper-responsiveness $(\mathrm{AHR})^{12}$ and reverse impaired $\beta$-adrenoceptor responsiveness induced by airway inflammation. ${ }^{13}$
In human tissue, statins reduce mast cell degranulation, ${ }^{14}$ enhance inflammatory cell apoptosis ${ }^{15}$ and inhibit airway smooth muscle proliferation. ${ }^{16}$

To our knowledge, only two clinical studies investigating statins in asthma have been published. ${ }^{17} 18$ The scope of these was limited. The first was of short duration (1 month), with a small number of patients $(n=16) .{ }^{17}$ In the second, inhaled corticosteroid (ICS) treatment was continued, and anti-inflammatory and steroid-sparing effects may have been masked. ${ }^{18}$

Our aim was to assess the steroid-sparing effects of simvastatin in patients with asthma. Our hypothesis was that with simvastatin, patients would require lower doses of ICS to maintain control. We conducted a randomised, double-blind, placebo-controlled, crossover study of simvastatin in which down-titration of ICS treatment was systematically undertaken.

\section{METHODS}

See also the Online repository.

\section{Patients}

Patients with stable persistent asthma were enrolled. Exclusion criteria are given in the Online repository.

\section{Phase1}

All patients completed a 2 -week run-in on regular medications, then ICS treatment was withdrawn until loss of control (LOC) or 28 days. This was followed by an open-label trial of inhaled fluticasone (1000 $\mu$ g daily for $\geq 28$ days). The aim of Phase 1 was to define the off-steroid inflammatory cell phenotype and the magnitude of steroid responsiveness. For further details. see Cowan et al. ${ }^{19}$

\section{Phase 2}

Patients proceeded to randomisation if, off steroid, they demonstrated one of the following: a provocation dose of hypertonic saline causing a $15 \%$ fall in forced expiratory volume in $1 \mathrm{~s}\left(\mathrm{FEV}_{1}\right)\left(\mathrm{PD}_{15}\right)$ of $<12 \mathrm{ml}^{20}$; a provocation dose of methacholine causing a $20 \%$ fall in $\mathrm{FEV}_{1}\left(\mathrm{PD}_{20}\right)$ of $<8 \mu \mathrm{mol}^{21}$; or an increase in $\mathrm{FEV}_{1}$ postbronchodilator $\geq 12 \%{ }^{22}$ All randomised patients had sputum eosinophilia $\geq 2 \%{ }^{23}$ : non-eosinophilic patients were excluded.

\section{Study design}

This was a randomised, double-blind, placebocontrolled, crossover trial of simvastatin, with stepwise down-titration of ICS dose during each treatment arm. Patients took a capsule containing either active drug (simvastatin 40 mg; Lipex, Merck Sharp Dohme, Auckland, New Zealand) or matching 
placebo once daily at night. The investigators were blinded to treatment allocation. In addition, each month, patients were supplied with two inhalers (A and B) and took one puff of inhaler $A$ in the morning and one puff of inhaler $B$ in the evening. The ICS dose was blinded to the patient by coupling unlabelled inhaler sleeves with actuators containing fluticasone 50, 125 or $250 \mu \mathrm{g}$, or placebo (0 $\mu \mathrm{g}$ ) (Flixotide, GlaxoSmithKline, Greenford, UK). Different $A$ and $B$ combinations provided for daily doses of 0,50 , 100,250 or $500 \mu \mathrm{g}$.

Patients were commenced at a dose of fluticasone of $500 \mu \mathrm{g} /$ day. If asthma was not controlled during the first month, the dose was stepped up to $1000 \mu \mathrm{g} /$ day for 1 month before commencing down-titration. If asthma was controlled, patients were given the next treatment pack and returned a month later. The dose of fluticasone was then stepped down at monthly intervals until LOC based on a priori criteria ${ }^{24}$ (figure 1). At LOC, or after 1 month taking $0 \mu \mathrm{g}$ /day fluticasone, sputum induction and AMP challenge were performed. Patients with no LOC at $0 \mu \mathrm{g} /$ day were crossed over to the alternative treatment and the sequence was repeated. Patients who experienced LOC then received fluticasone at a dose one step up from the one at which LOC had occurred. They were reviewed monthly with stepwise increases in fluticasone until control was regained (deemed to be the 'minimum dose requirement'). Sputum induction and AMP challenge were repeated at the 'minimum' dose, and patients then proceeded to the alternative arm.
Daytime symptoms, night waking, bronchodilator use and peak flows were recorded daily.

\section{Procedures at monthly reviews}

Patients completed the Asthma Control Questionnaire (ACQ), Asthma Control Test (ACT) and Asthma Quality of Life Questionnaire (AOLO) before having their fraction of exhaled nitric oxide $\left(\mathrm{F}_{\mathrm{E}} \mathrm{NO}\right)$ and spirometry measured.

\section{Ethical and safety considerations}

All patients gave written informed consent. Safety procedures, including adverse drug event monitoring, are documented in the Online repository. Ethical approval was obtained from the Lower South Regional Ethics Committee, New Zealand.

This study was registered with the Australian New Zealand Clinical Trials Registry (ACTRN12606000531516).

\section{Study size and statistical analyses (see Online repository)}

The primary end point was 'minimum' ICS dose requirement. Secondary end points were ICS dose at LOC, and number of patients without LOC after ICS withdrawal. Based on previous data, ${ }^{25}$ and using a SD of $200 \mu \mathrm{g}$ for mean daily fluticasone dose requirement, it was calculated that to demonstrate the superiority of simvastatin in reducing the 'minimum' dose requirement by $100 \mu \mathrm{g}, 33$ patients would be required (power $=80 \%$, $\alpha=0.05$ and $\beta=0.2$ ). Additional patients were recruited to allow

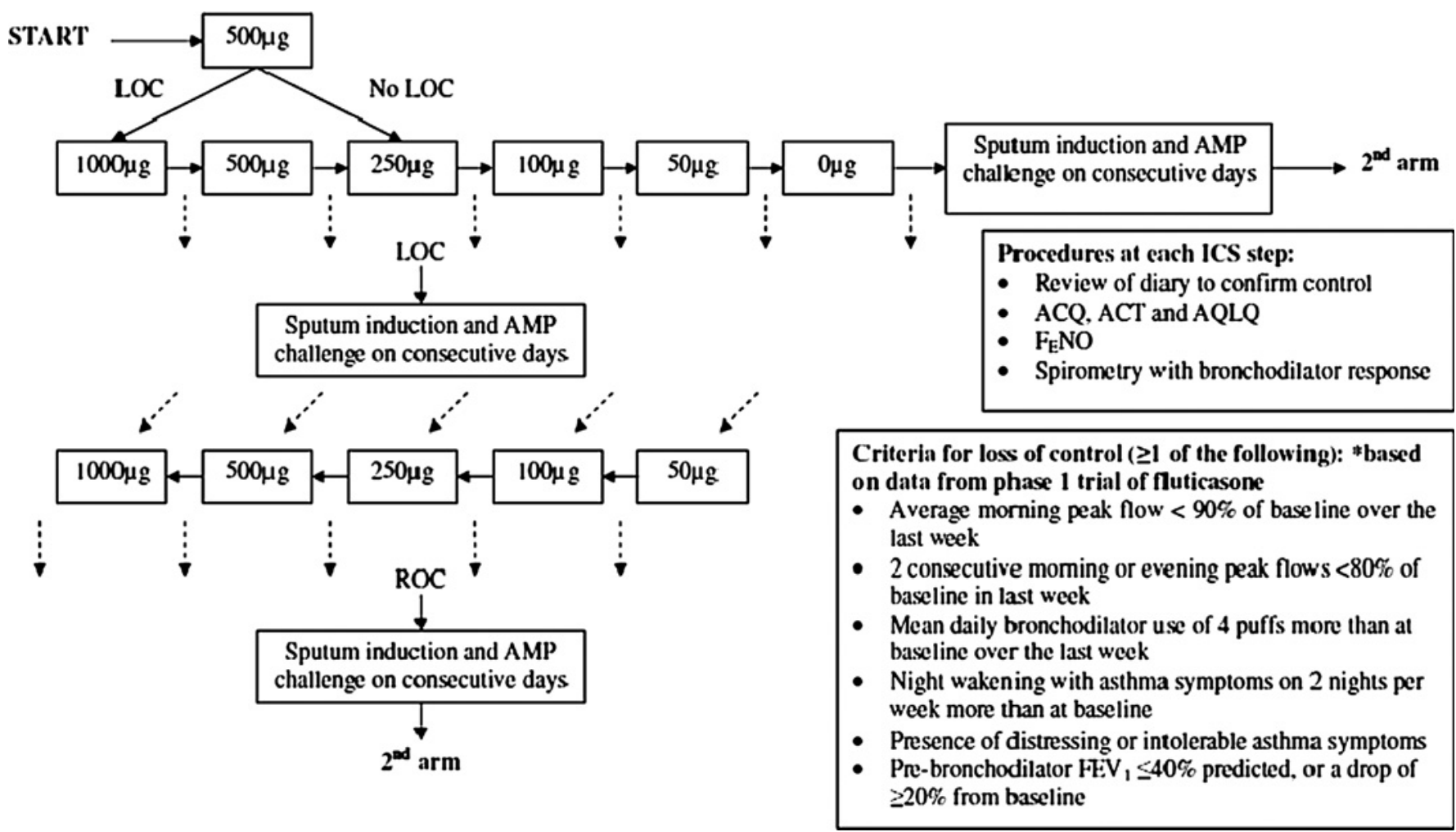

Figure 1 Protocol for the first arm of study (second arm identical). Patients were randomised to either simvastatin $40 \mathrm{mg}$ at night or placebo during the first arm, and were crossed over to receive the alternative treatment in the second arm. Monthly changes in daily fluticasone dose are shown in boxes. Subjects commenced on $500 \mu \mathrm{g}$ daily, and stepwise reduction occurred each month until either loss of control (LOC) or $0 \mu \mathrm{g} / \mathrm{day}$ was reached. Sputum induction and AMP challenge were then performed. Subjects reaching $0 \mu \mathrm{g}$ without LOC ('minimum required' dose $=0 \mu \mathrm{g} / \mathrm{day}$ ) then proceeded to the second arm. Subjects with LOC were provided with the fluticasone dose one step up from that at which LOC occurred. They were reviewed monthly with stepwise increase in fluticasone dose each month until regain of control (ROC) occurred ('minimum required' dose), at which time sputum induction and AMP challenge were repeated before progressing to the second arm. ${ }^{*}$ Criteria for loss of control were based on diary data and spirometry from the last 2 weeks of the Phase 1 trial of fluticasone. ACQ, Asthma Control Questionnaire; AQLQ, Asthma Quality of Lfe Questionnaire; $F_{E} N 0$, fraction of exhaled nitric oxide; $F_{E V}$, forced expiratory volume in $1 \mathrm{~s}$; ICS, inhaled corticosteroid (fluticasone). 
for a drop-out rate of $25 \%$. Paired survival analysis was used to compare the proportions of patients who reached LOC at each treatment step on simvastatin and placebo, using Cox proportional hazards regression clustered on the individual. Proportions with LOC on simvastatin and placebo were compared using McNemar test. ICS dose at LOC and 'minimum' ICS dose on simvastatin and placebo were compared using Wilcoxon signed rank sum tests. Other comparisons were made using paired $t$ tests and Wilcoxon signed rank sum tests. For the purposes of the study, asthma control was deemed to be the absence of the criteria used to define LOC. Statistical correction for multiple comparisons was not undertaken and the possibility exists that some results occurred by chance despite a $\mathrm{p}$ value $<0.05$

\section{RESULTS}

Fifty-one subjects were randomised; 43 completed both treatment arms. Baseline characteristics are shown in table 1 . There were eight withdrawals: three before commencing treatment (pregnancy, deranged liver function, withdrawal of consent); four during the simvastatin arm (muscle pain, rash, troublesome asthma, relocation); and one during the placebo arm (pregnancy). Data for these eight subjects were not analysed; their baseline characteristics did not differ from those who completed the study. Following the prerandomisation trial of fluticasone, as expected, there were significant changes for ACQ (mean (SD) -1.2 (0.9) points, $\mathrm{p}<0.001$ ), $\mathrm{FEV}_{1}$ (mean (SD) +0.67 (0.41) litres, $\mathrm{p}<0.001$ ) and $\mathrm{PC}_{20} \mathrm{AMP}$ (mean (SD) doubling dose increase 3.7 (2.8), $\mathrm{p}<0.001$; table R1, Online repository).

\section{LOC during stepwise ICS dose reduction}

With down-titration, the number of subjects who lost control at each treatment step did not differ significantly between simvastatin and placebo ( $p=0.404$; figure 2$)$. LOC occurred in 26 subjects $(60 \%)$ during both simvastatin and placebo arms, in 3 (7\%) during the simvastatin arm only, and in $6(14 \%)$ during the placebo arm only. There was no order effect. In 8 (19\%), LOC did not occur in either arm $(p=0.508)$, and thus for this

Table 1 Characteristics of study participants at study entry

\begin{tabular}{|c|c|}
\hline & $n=43$ \\
\hline Age (years) mean (range) & $45(20-68)$ \\
\hline Male* & $14(33 \%)$ \\
\hline Age of onset (years)† & $14(0-33)$ \\
\hline Ex-smokers* & $12(28 \%)$ \\
\hline Atopic* & $35(81 \%)$ \\
\hline On ICS* & $42(98 \%)$ \\
\hline On $\mathrm{LABA}^{*}$ & $17(40 \%)$ \\
\hline ICS dose ( $\mu \mathrm{g}$ daily) $\dagger \neq$ & $1000(500-1000)$ \\
\hline ACO & $0.8(0.6)$ \\
\hline $\mathrm{FEV}_{1} \%$ predicted & $86(19)$ \\
\hline $\mathrm{FEV}_{1} / \mathrm{FVC}(\%)$ & $68(10)$ \\
\hline $\mathrm{FEV}_{1} \%$ change postbronchodilator $\dagger$ & $9(5-15)$ \\
\hline $\mathrm{F}_{\mathrm{E}} \mathrm{NO}(\mathrm{ppb}) \S$ & $30.9(25.3-37.8)$ \\
\hline \multicolumn{2}{|c|}{$\begin{array}{l}\text { Data expressed as mean (SD) unless otherwise stated. } \\
\text { *Expressed as } \mathrm{n}(\%) \text {. } \\
\text { †Expressed as median (IQR). } \\
\text { †Beclomethasone equivalent: } 1 \mu \mathrm{g} \text { beclomethasone }=1 \mu \mathrm{g} \text { budesonide } \\
=0.5 \mu \mathrm{g} \text { fluticasone. } \\
\text { §Expressed as geometric mean }(95 \% \mathrm{Cl}) \text {. } \\
\text { ACQ, Asthma Control Questionnaire; } \mathrm{F}_{\mathrm{E}} \mathrm{NO} \text {, fraction of exhaled nitric } \\
\text { oxide; FEV }{ }_{1} \text {, forced expiratory volume in } 1 \mathrm{~s} \text {; FVC, forced vital capacity; } \\
\text { ICS, inhaled corticosteroid; LABA, long-acting } \beta \text {-agonist. }\end{array}$} \\
\hline
\end{tabular}

subgroup, 'minimum' ICS dose was $0 \mu \mathrm{g} /$ day with both simvastatin and placebo. In patients with LOC during both treatment arms $(n=26)$, the fluticasone dose at LOC was not significantly different between the simvastatin and placebo arms; median (IOR) for both, $50 \mu \mathrm{g} /$ day $(0-100)(\mathrm{p}=0.620)$.

\section{'Minimum' fluticasone dose and asthma control}

At 'minimum' fluticasone dose, ACQ was similar with both simvastatin and placebo (median (IOR) 0.3 (0.0-1.1) and 0.7 $(0.3-1.2)$, respectively, $p=0.171$ ) (table 2 ). There was no significant difference in the 'minimum' fluticasone dose between the simvastatin and placebo arms; median (IOR) $50 \mu \mathrm{g} /$ day (0-250) and $100 \mu \mathrm{g} /$ day $(0-250)$, respectively $(p=0.931)$. The distribution of 'minimum' doses with simvastatin or placebo did not differ significantly $\left(\chi^{2}=9.94, p=0.269\right.$; figure 3$)$. Similarly, ACT, $\mathrm{AQLQ}, \mathrm{FEV}_{1}$ and AHR were not significantly different between treatment arms at 'minimum' fluticasone dose (table 2). However, at 'minimum' dose, sputum eosinophils were lower (median (IOR) 9.9\% (5.7-27.0) vs 22.7\% (13.4-37.8), $\mathrm{p}=0.047$ ) with simvastatin than placebo. None of the mediators in sputum supernatant differed significantly between the two treatment arms (table R2, Online repository).

\section{Comparisons at each fluticasone dose step}

Paired data were available at each fluticasone dose as follows: $500 \mu \mathrm{g}, \mathrm{n}=43 ; 250 \mu \mathrm{g}, \mathrm{n}=43 ; 100 \mu \mathrm{g}, \mathrm{n}=36 ; 50 \mu \mathrm{g}, \mathrm{n}=30 ; 0 \mu \mathrm{g}$, $\mathrm{n}=18$ (table 3). At $500 \mu \mathrm{g}$, morning peak expiratory flow (PEF) was significantly higher on placebo than on simvastatin $(p=0.007)$. At $0 \mu \mathrm{g} /$ day, $A C Q$ was significantly lower $(p=0.037)$, and both prebronchodilator and postbronchodilator $\mathrm{FEV}_{1}$ were significantly higher on simvastatin than on placebo $(\mathrm{p}<0.001$ and $p<0.01$, respectively). No other significant differences were seen.

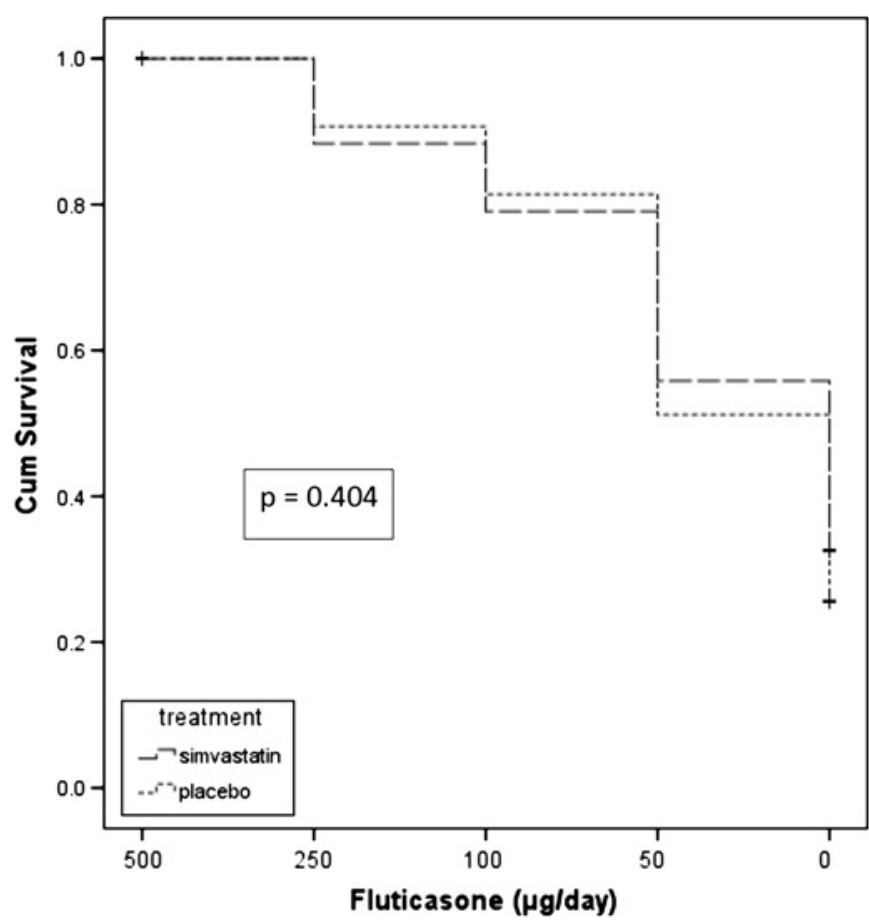

Figure 2 Kaplan-Meier plot showing the number of subjects without loss of control at each fluticasone dose during monthly stepwise dose reduction from $500 \mu \mathrm{g} /$ day to $0 \mu \mathrm{g} /$ day with simvastatin and placebo. There was no significant difference between simvastatin and placebo $(p=0.404)$. 
Table 2 Comparison of symptoms (ACQ, ACT), quality of life (AOLO), bronchodilator use, lung function (PEF and $\left.F E V_{1}\right)$, airway hyperresponsiveness $\left(\mathrm{PC}_{20} \mathrm{AMP}\right)$ and airway inflammation $\left(\mathrm{F}_{\mathrm{E}} \mathrm{NO}\right.$ and sputum cells) in all patients at 'minimum' dose while taking concomitant simvastatin $40 \mathrm{mg}$ at night or placebo

\begin{tabular}{|c|c|c|c|}
\hline & Simvastatin & Placebo & p Value \\
\hline $\mathrm{ACO}$ & $0.3(0.0-1.1)$ & $0.7(0.3-1.2)$ & 0.171 \\
\hline ACT & $22(19-24)$ & $21(18-24)$ & 0.425 \\
\hline AOLO & $6.7(6.3-6.9)$ & $6.6(5.9-6.8)$ & 0.150 \\
\hline Salbutamol use (puffs/24 h) & $0(0-0.8)$ & $0.2(0-0.8)$ & 0.731 \\
\hline Mean morning PEF (I/min) & $415(110)$ & 408 (107) & 0.063 \\
\hline Mean evening PEF (I/min) & 423 (112) & $418(108)$ & 0.149 \\
\hline Pre-BD FEV 1 (litres) & $2.61(0.72)$ & $2.62(0.75)$ & 0.659 \\
\hline Post-BD FEV ${ }_{1}$ (litres) & $2.92(0.78)$ & $2.90(0.79)$ & 0.539 \\
\hline $\mathrm{PC}_{20} \mathrm{AMP}(\mathrm{mg} / \mathrm{mll})^{*}$ & $32.5(17.8-59.7)$ & $46.3(23.9-89.7)$ & 0.144 \\
\hline $\mathrm{F}_{\mathrm{E}} \mathrm{NO}(\mathrm{ppb})^{*}$ & $31.7(26.4-38.2)$ & $27.3(22.0-33.8)$ & 0.098 \\
\hline Eosinophils (\%) & $9.9(5.7-27.0)$ & $22.7(13.4-37.8)$ & 0.047 \\
\hline Neutrophils (\%) & $23.6(9.1-47.4)$ & $14.5(6.3-27.5)$ & 0.030 \\
\hline Macrophages (\%) & $33.0(19.3-57.0)$ & $36.3(25.1-55.8)$ & 0.400 \\
\hline Lymphocytes (\%) & $0.7(0.3-1.8)$ & $0.7(0.0-1.5)$ & 0.429 \\
\hline
\end{tabular}

Comparisons are by paired t tests (presented as mean (SD)) and Wilcoxon signed rank tests (presented as median (IQR)).

$\mathrm{p}$ Values are for comparisons between simvastatin and placebo; significant values are in bold.

${ }^{*}$ Analysed by paired $t$ test after logarithmic transformation; results presented as geometric mean $(95 \% \mathrm{Cl})$.

ACQ, Asthma Control Questionnaire; ACT, Asthma Control Test; AOLO, Asthma Quality of Life Questionnaire; $\mathrm{BD}$, bronchodilator; $\mathrm{F}_{\mathrm{E}} \mathrm{NO}$, fraction of exhaled nitric oxide; $\mathrm{FEV}_{1}$, forced expiratory volume in $1 \mathrm{~s} ; \mathrm{PC}_{20} \mathrm{AMP}$, provocation concentration of $\mathrm{AMP}$ causing a $20 \%$ fall in $\mathrm{FEV}_{1} ; \mathrm{PEF}$, peak expiratory flow.

\section{AHR, sputum cells and cytokines}

In the subgroup who were down-titrated to $0 \mu \mathrm{g}$ fluticasone ( $\mathrm{n}=18$, of whom 8 did not experience LOC), $\mathrm{PC}_{20} \mathrm{AMP}$ was similar with both simvastatin and placebo (table 4). Sputum eosinophils were significantly lower $(p=0.033)$ and lymphocytes significantly higher $(p=0.003)$ with simvastatin. There were no significant differences in any of the sputum mediators between simvastatin and placebo (table R3, Online repository).

\section{DISCUSSION}

This is the first study to assess the steroid-sparing effects of simvastatin in patients with eosinophilic, steroid-responsive

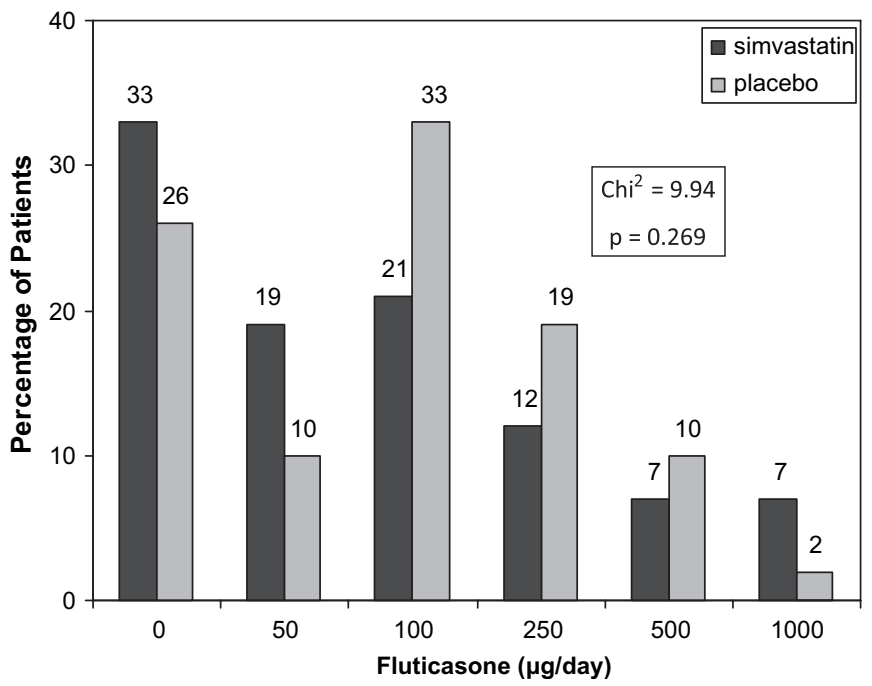

Figure 3 Number of patients (\%) whose 'minimum' maintenance dose of inhaled fluticasone was $0,50,100,250,500$ and $1000 \mu \mathrm{g} /$ day while taking simvastatin $40 \mathrm{mg}$ at nightor placebo. asthma. Our principal finding was that simvastatin was not associated with a clinically important steroid-sparing effect. The 'minimum' steroid dose required to establish asthma control was the same whether taking simvastatin or placebo. Similarly, the dose at which LOC occurred following steroid reduction was comparable in both treatment arms, and in patients who experienced LOC in both arms, the steroid dose at which it occurred was no different.

In patients in whom steroid treatment was reduced to $0 \mu \mathrm{g} /$ day ( $n=18$, of whom 10 lost control), simvastatin was associated with minor improvements in ACQ and $\mathrm{FEV}_{1}$ (table 3). Simultaneously, sputum eosinophils were reduced with simvastatin (from $25.4 \%$ to $9.5 \%, \mathrm{p}=0.033$ ). In all patients, when taking their 'minimum required' fluticasone dose, sputum eosinophils were significantly lower with simvastatin $(9.9 \%$ vs $22.7 \%, p=0.047)$, despite the fact that the mean 'minimum' dose was almost identical (168 vs $157 \mu \mathrm{g} /$ day). Taken together, these data suggest that although an anti-inflammatory effect may occur with simvastatin, it was insufficient to have any significant impact on steroid requirements. Our data pertaining to sputum eosinophilia are in keeping with animal-based studies ${ }^{10} 11$ which showed reduced eosinophils after allergen challenge in statin-treated mice.

Despite a reduction in sputum eosinophils with simvastatin, there were no differences in AHR or sputum mediators (interleukin 4 (IL-4), IL-5 or eotaxin). The dissociation between changes in inflammatory cells versus AHR and symptoms has been reported with anti-IL-5 treatment. ${ }^{26}$ In an in vitro study of eosinophils from patients with asthma, simvastatin induces apoptosis, ${ }^{27}$ and lovastatin enhances phagocytic clearance of apoptotic cells. ${ }^{15}$ Thus the reduction in sputum eosinophils with simvastatin may result from apoptosis induction and/or increased eosinophil clearance.

At 'minimum required' fluticasone dose, sputum eosinophils remained increased. Despite unresolved sputum eosinophilia, the median ACQ was 0.3 with simvastatin and 0.7 with placebo (non-significant), indicating adequate asthma control. ${ }^{28}$ Changes in sputum eosinophils may be out of phase with asthma control by up to 20 days. ${ }^{29}$ In addition, steroid withdrawal may result in 'rebound' eosinophilia. ${ }^{30}$ These phenomena may explain why sputum eosinophils remained elevated at 'minimum' dose, yet with relative suppression of eosinophils with simvastatin compared with placebo.

Non-eosinophilic patients were excluded so that the effect of treatment specifically on the eosinophilic phenotype could be assessed. We avoided recruiting 'all-comers' in whom treatment response is more likely to be variable. ${ }^{31}$ Asthma is pathologically heterogeneous, as is the response to disease-modifying treatments. Ideally clinical trials should include patients with a similar pathological phenotype. This is illustrated in studies of the anti-IL-5 antibody, mepolizumab. ${ }^{26} 3233$ Whereas outcomes in unselected patients were disappointing, ${ }^{33}$ in later studies patients with an eosinophilic phenotype were selected ${ }^{26} 32$ and positive outcomes were achieved, indicating that matching treatment to phenotype is important. Further studies are needed to investigate the effects of statins in non-eosinophilic asthma in the light of promising outcomes in COPD..$^{5-7} 3435$

There are only two clinical studies that have previously assessed statins in asthma. ${ }^{17}{ }^{18}$ In the first small study $(n=16),{ }^{17}$ simvastatin was given for 4 weeks. In the second ${ }^{18}(n=54)$, atorvastain ( $40 \mathrm{mg}$ daily) was administered for 8 weeks, but regular ICS treatment was continued. Neither study demonstrated important differences between statin and placebo for symptoms, spirometry or AHR, although sputum leukotriene B4 and macrophages decreased significantly with atorvastatin. ${ }^{18}$ 
Table 3 Measures of asthma control during stepwise reduction in ICS dose while taking simvastatin and placebo

\begin{tabular}{|c|c|c|c|c|c|c|c|c|c|c|c|}
\hline $\begin{array}{l}\text { Fluticasone dose } \\
(\mu \mathrm{g} / \text { day })\end{array}$ & & $500(n=43)$ & $\begin{array}{l}\mathbf{p} \\
\text { Value }\end{array}$ & $250(n=43)$ & $\begin{array}{l}p \\
\text { Value }\end{array}$ & $100(n=36)$ & $\begin{array}{l}p \\
\text { Value }\end{array}$ & $50(n=30)$ & $\begin{array}{l}\mathbf{p} \\
\text { Value }\end{array}$ & $0(n=18)$ & $\begin{array}{l}p \\
\text { Value }\end{array}$ \\
\hline \multirow[t]{2}{*}{ ACQ } & $\operatorname{Sim}$ & $0.5(0.0-1.2)$ & 0.182 & $0.5(0.2-1.3)$ & 0.603 & $0.3(0.0-1.2)$ & 0.764 & $0.5(0.0-1.7)$ & 0.435 & $0.4(0.0-1.8)$ & 0.037 \\
\hline & $\mathrm{Pla}$ & $0.3(0.0-0.8)$ & & $0.4(0.0-1.0)$ & & $0.5(0.0-1.2)$ & & $0.7(0.4-1.6)$ & & $1.2(0.3-2.9)$ & \\
\hline АСТ & $\mathrm{Pla}$ & $23(20-25)$ & & $23(18-24)$ & & $22(19-25)$ & & $21(19-24)$ & & $19(16-24)$ & \\
\hline \multirow[t]{2}{*}{ AQLO } & $\operatorname{Sim}$ & $6.7(6.2-6.9)$ & 0.339 & $6.6(6.0-6.9)$ & 0.547 & $6.8(6.5-6.9)$ & 0.855 & $6.7(6.0-6.9)$ & 0.236 & $6.7(5.5-6.9)$ & 0.088 \\
\hline & $\mathrm{Pla}$ & $6.8(6.5-6.9)$ & & $6.7(6.3-6.9)$ & & $6.8(6.1-6.9)$ & & $6.5(6.0-6.8)$ & & $6.3(5.0-6.7)$ & \\
\hline \multirow[t]{2}{*}{ Mean morning PEF (I/min) } & Sim & 412 (119) & 0.007 & $410(118)$ & 0.076 & 417 (124) & 0.946 & $414(121)$ & 0.663 & 441 (112) & 0.160 \\
\hline & $\mathrm{Pla}$ & $426(116)$ & & 416 (118) & & $417(124)$ & & $416(116)$ & & $430(104)$ & \\
\hline \multirow[t]{2}{*}{ Mean evening PEF (I/min) } & $\operatorname{Sim}$ & $414(116)$ & 0.006 & 415 (118) & 0.250 & $421(125)$ & 0.730 & $422(119)$ & 0.763 & $447(111)$ & 0.219 \\
\hline & $\mathrm{Pla}$ & $428(117)$ & & $420(117)$ & & $419(123)$ & & $420(118)$ & & 438 (99) & \\
\hline \multirow[t]{2}{*}{ Pre-BD FEV ${ }_{1}$ (litres) } & $\operatorname{Sim}$ & $2.66(0.78)$ & 0.677 & $2.61(0.78)$ & 0.566 & $2.62(0.79)$ & 0.455 & $2.58(0.79)$ & 0.552 & $2.79(0.69)$ & 0.001 \\
\hline & $\mathrm{Pla}$ & $2.65(0.77)$ & & $2.58(0.77)$ & & $2.58(0.82)$ & & $2.60(0.78)$ & & $2.64(0.69)$ & \\
\hline
\end{tabular}

Comparison of symptoms ( $\mathrm{ACQ}, \mathrm{ACT})$, quality of life (AOLO), bronchodilator use, lung function ( $\mathrm{PEF}$ and $\mathrm{FEV}_{1}$ ) and airway inflammation $\left(\mathrm{F}_{\mathrm{E}} \mathrm{NO}\right)$ in those patients with paired measurements obtained at $500,250,100,50$ and $0 \mu \mathrm{g}$ daily of inhaled fluticasone during stepwise reduction while taking concomitant simvastatin $40 \mathrm{mg}$ at night or placebo.

$\mathrm{p}$ values are for comparisons of simvastatin and placebo; significant values are in bold.

Comparison are by paired t tests (presented as mean (SD)) and Wilcoxon signed rank tests (presented as median (IQR)).

${ }^{*}$ Analysed by paired $t$ test after logarithmic transformation and results presented as geometric mean $(95 \% \mathrm{Cl})$.

ACQ, Asthma Control Questionnaire; ACT, Asthma Control Test; AOLO, Asthma Quality of Life Questionnaire; BD, bronchodilator; $F_{E} N O$, fraction of exhaled nitric oxide; FEV 1 , forced expiratory volume in $1 \mathrm{~s}$; PEF, peak expiratory flow; Pla, placebo; Sim, simvastatin.

However, there are weaknesses in their design. First, treatment duration was relatively short. ${ }^{17}$ In our study, length of treatment depended on when/whether a patient reached LOC, but all received a minimum of 3 months treatment. Secondly the study by Menzies et $a^{17}$ was, by the authors' own admission, underpowered to detect changes in airway inflammation. Thirdly, in the study by Hothersall et al, ${ }^{18}$ patients continued ICS throughout, and masking of any anti-inflammatory effect of statin was therefore possible. In the Menzies study, ${ }^{17}$ even after ICS withdrawal, the sputum eosinophil count was $2 \%$, suggesting minimal eosinophilic airway inflammation. By recruiting a broad spectrum of patients, neither study was designed to evaluate statin treatment in specific inflammatory phenotypes.

We used simvastatin at a dose of $40 \mathrm{mg}$ daily. Data from several studies supported the selection of simvastatin as the trial drug. In murine models, simvastatin reduces eosinophilic inflammation $^{10}{ }^{12}$ and AHR, ${ }^{12}$ while in vitro human studies indicate that simvastatin induces eosinophil apoptosis ${ }^{27}$ and

Table 4 Comparison of airway hyper-responsiveness ( $\left.\mathrm{PC}_{20} \mathrm{AMP}\right)$ and sputum cells at $0 \mu \mathrm{g}$ fluticasone daily in the subgroup $(n=18)$ reaching this dose after stepwise reduction while taking concomitant simvastatin $40 \mathrm{mg}$ at night or placebo

\begin{tabular}{lcll}
\hline & Simvastatin & Placebo & p Value \\
\hline $\mathrm{PC}_{20} \mathrm{AMP}(\mathrm{mg} / \mathrm{ml})^{*}$ & $27.4(12.2$ to 61.6$)$ & $47.6(16.7$ to 135.7$)$ & 0.144 \\
Eosinophils $\%$ ) & $9.5(5.7-31.1)$ & $25.4(15.2-48.2)$ & $\mathbf{0 . 0 3 3}$ \\
Neutrophils (\%) & $20.2(11.3-51.3)$ & $16.1(4.9-35.5)$ & 0.145 \\
Macrophages (\%) & $34.0(19.9-56.9)$ & $28.6(16.6-45.6)$ & 0.215 \\
Lymphocytes (\%) & $1.8(0.7-3.0)$ & $0.7(0.0-1.4)$ & $\mathbf{0 . 0 0 3}$ \\
\hline
\end{tabular}

$\mathrm{p}$ Values are for comparisons between simvastatin and placebo; significant values are in bold.

Analysed using Wilcoxon signed rank tests.

Data are expressed as median (IOR).

*Analysed by paired $t$ test after logarithmic transformation and results presented as geometric mean $(95 \% \mathrm{Cl})$.

$\mathrm{PC}_{20} \mathrm{AMP}$, provocation concentration of AMP causing a $20 \%$ fall in forced expiratory volume in $1 \mathrm{~s}$. inhibits proliferation of airway smooth muscle cells. ${ }^{16}$ The choice of dose ( $40 \mathrm{mg}$ daily) was based on data demonstrating anti-inflammatory effects (reduced serum IL-6, IL-8 and monocyte chemoattractant protein-1) at this dose. ${ }^{36}$ We cannot exclude that lack of clinical effect may be because the dose of simvastatin was too low.

A subgroup of patients had no LOC after ICS withdrawal: this occurred in $8(19 \%)$ in both treatment arms, in $6(14 \%)$ with simvastatin and 3 (7\%) with placebo; their 'minimum' ICS dose requirement was $0 \mu \mathrm{g}$ /day. Arguably, the inclusion of patients with mild asthma may have reduced the potential to show a treatment effect. However, at the study outset, of 43 patients who were enrolled, 42 (98\%) were taking regular ICS and 17 $(40 \%)$ were also taking a regular long-acting $\beta$-agonist. Moreover, after ICS withdrawal in Phase 1, 36 (84\%) demonstrated LOC, indicating that they were 'steroid requiring'. The duration of each step during ICS dose reduction was 1 month. If the interval between adjustments had been longer, LOC may have occurred in these patients, and consequently the calculated 'minimum dose' requirement would have been higher. Reassuringly, a posthoc analysis of patients who experienced LOC during ICS reduction ( $n=36,84 \%$ ) revealed no significant difference between simvastatin and placebo (Online repository: figure R1).

In conclusion, our results suggest that statin treatment is unlikely to be beneficial in managing specifically eosinophilic asthma. No clinically important steroid-sparing effects were demonstrated. In the absence of steroid, simvastatin is associated with minor improvements in symptoms and lung function, together with reduced sputum eosinophils, the relevance of which is unclear. Given the apparent benefits of statin treatment reported in epidemiological studies of COPD, it may be that in other airways disease phenotypes, statins may have a role.

Acknowledgements We thank Ms Sarah Featherston for her administrative support, Dr Sarah Young for her expertise in measurement of sputum supernatant fluid mediators, and Professor G. Peter Herbison and Dr Erik Landhuis for their 
statistical advice. We are grateful to Professor Louis-Philippe Boulet who provided helpful comments on this manuscript.

Funding Lottery Health New Zealand, the Asthma and Respiratory Foundation of New Zealand and the Dean of the Dunedin School of Medicine (Distinguished Researcher Award).

\section{Competing interests None.}

Patient consent Obtained.

Ethics approval This study was conducted with the approval of the Lower South Island Ethics Committee, New Zealand.

Contributors DCC conducted the study and was responsible for analysing the data and writing the manuscript; JOC, RP and AW provided technical support; DRT designed the study, supervised its conduct and wrote the manuscript.

Provenance and peer review Not commissioned; externally peer reviewed.

\section{REFERENCES}

1. Kurian KC, Rai P, Sankaran S, et al. The effect of statins in heart failure: beyond its cholesterol-lowering effect. J Card Fail 2006;12:473-8.

2. Anon. Randomised trial of cholesterol lowering in 4444 patients with coronary heart disease: the Scandinavian Simvastatin Survival Study (4S). Lancet 1994;344:1383-9.

3. Vollmer T, Key L, Durkalski V, et al. Oral simvastatin treatment in relapsing-remitting multiple sclerosis. Lancet 2004;363:1607-8.

4. McCarey DW, Mclnnes IB, Madhok R, et al. Trial of Atorvastatin in Rheumatoid Arthritis (TARA): double-blind, randomised placebo-controlled trial. Lancet 2004;363:2015-21.

5. Young RP, Hopkins R, Eaton TE. Potential benefits of statins on morbidity and mortality in chronic obstructive pulmonary disease: a review of the evidence. Postgrad Med J 2009;85:414-21.

6. Alexeeff SE, Litonjua AA, Sparrow D, et al. Statin use reduces decline in lung function: VA Normative Aging Study. Am J Respir Crit Care Med 2007:176:742-7.

7. Soyseth V, Brekke PH, Smith P, et al. Statin use is associated with reduced mortality in COPD. Eur Respir J 2007;29:279-83.

8. Lee TM, Chen CC, Shen HN, et al. Effects of pravastatin on functional capacity in patients with chronic obstructive pulmonary disease and pulmonary hypertension. Clin Sci (Lond) 2009;116:497-505.

9. Samson KT, Minoguchi K, Tanaka A, et al. Inhibitory effects of fluvastatin on cytokine and chemokine production by peripheral blood mononuclear cells in patients with allergic asthma. Clin Exp Allergy 2006;36:475-82.

10. McKay A, Leung BP, Mclnnes IB, et al. A novel anti-inflammatory role of simvastatin in a murine model of allergic asthma. J Immunol 2004;172:2903-8.

11. Yeh YF, Huang SL. Enhancing effect of dietary cholesterol and inhibitory effect of pravastatin on allergic pulmonary inflammation. J Biomed Sci 2004;11:599-606.

12. Zeki AA, Franzi L, Last J, et al. Simvastatin inhibits airway hyperreactivity: implications for the mevalonate pathway and beyond. Am J Respir Crit Care Med 2009:180:731-40.

13. Clements JD, Jamali F. Pravastatin reverses the down-regulating effect of inflammation on beta-adrenergic receptors: a disease-drug interaction between inflammation, pravastatin, and propranolol. Vascul Pharmacol 2007:46:52-9.

14. Krauth MT, Majlesi Y, Sonneck K, et al. Effects of various statins on cytokine-dependent growth and IgE-dependent release of histamine in human mast cells. Allergy 2006;61:281-8.

15. Morimoto K, Janssen WJ, Fessler MB, et al. Lovastatin enhances clearance of apoptotic cells (efferocytosis) with implications for chronic obstructive pulmonary disease. J Immunol 2006;176:7657-65.
16. Takeda N, Kondo $\mathrm{M}$, Ito $\mathrm{S}$, et al. Role of RhoA inactivation in reduced cell proliferation of human airway smooth muscle by simvastatin. Am J Respir Cell Mol Biol 2006;35:722-9.

17. Menzies D, Nair A, Meldrum KT, et al. Simvastatin does not exhibit therapeutic anti-inflammatory effects in asthma. J Allergy Clin Immunol 2007:119:328-35

18. Hothersall EJ, Chaudhuri R, McSharry C, et al. Effects of atorvastatin added to inhaled corticosteroids on lung function and sputum cell counts in atopic asthma. Thorax 2008;63:1070-5.

19. Cowan DC, Cowan J0, Palmay R, et al. Effects of steroid therapy on inflammatory cell subtypes in asthma. Thorax 2010;65:384-90.

20. Anderson SD, Brannan JD. Methods for "indirect" challenge tests including exercise, eucapnic voluntary hyperpnea, and hypertonic aerosols. Clin Rev Allergy Immunol 2003;24:27-54.

21. Sterk PJ, Fabbri LM, Quanjer PH, et al. Airway responsiveness. Standardized challenge testing with pharmacological, physical and sensitizing stimuli in adults. Report Working Party Standardization of Lung Function Tests, European Community for Steel and Coal. Official Statement of the European Respiratory Society. Eur Respir J Supp/ 1993;16:53-83.

22. American Thoracic Society. Lung function testing: selection of reference values and interpretative strategies. Am Rev Respir Dis 1991;144:1202-18.

23. Reddel HK, Taylor DR, Bateman ED, et al. An official American Thoracic Society/ European Respiratory Society statement: asthma control and exacerbations: standardizing endpoints for clinical asthma trials and clinical practice. Am J Respir Crit Care Med 2009;180:59-99.

24. Jones SL, Kittelson J, Cowan JO, et al. The predictive value of exhaled nitric oxide measurements in assessing changes in asthma control. Am J Respir Crit Care Med 2001:164:738-43.

25. Smith AD, Cowan J0, Brassett KP, et al. Use of exhaled nitric oxide measurements to guide treatment in chronic asthma. N Engl J Med 2005;352:2163-73.

26. Haldar P, Brightling CE, Hargadon B, et al. Mepolizumab and exacerbations of refractory eosinophilic asthma. N Engl J Med 2009;360:973-84.

27. Luo FML, Li CT, Wang SQ, et al. Simvastatin induces eosinophil apoptosis in vitro Zhonghua Jie He He Hu Za Zhi 2005;28:320-3.

28. Juniper EF, Bousquet J, Abetz L, et al. Identifying 'well-controlled' and 'not well-controlled' asthma using the asthma control questionnaire. Respir Med 2006;100:616-21.

29. Belda J, Parameswaran K, Lemiere C, et al. Predictors of loss of asthma control induced by corticosteroid withdrawal. Can Respir J 2006:13:129-33.

30. van Rensen EL, Straathof KC, Veselic-Charvat MA, et al. Effect of inhaled steroids on airway hyperresponsiveness, sputum eosinophils, and exhaled nitric oxide levels in patients with asthma. Thorax 1999;54:403-8.

31. Szefler SJ, Martin RJ, King TS, et al. Significant variability in response to inhaled corticosteroids for persistent asthma. J Allergy Clin Immunol 2002:109:410-18.

32. Nair P, Pizzichini MM, Kjarsgaard M, et al. Mepolizumab for prednisone-dependent asthma with sputum eosinophilia. N Engl J Med 2009;360:985-93.

33. Flood-Page P, Swenson C, Faiferman I, et al. A study to evaluate safety and efficacy of mepolizumab in patients with moderate persistent asthma. Am J Respir Crit Care Med 2007:176:1062-71.

34. Keddissi JI, Younis WG, Chbeir EA, et al. The use of statins and lung function in current and former smokers. Chest 2007;132:1764-71.

35. Lee JH, Lee DS, Kim EK, et al. Simvastatin inhibits cigarette smoking-induced emphysema and pulmonary hypertension in rat lungs. Am J Respir Crit Care Med 2005:172:987-93.

36. Rezaie-Majd A, Maca T, Bucek RA, et al. Simvastatin reduces expression of cytokines interleukin-6, interleukin-8, and monocyte chemoattractant protein-1 in circulating monocytes from hypercholesterolemic patients. Arterioscler Thromb Vasc Biol 2002:22:1194-9. 